\title{
The effect of maternal fish oil supplementation during the last trimester of pregnancy on blood pressure, heart rate and heart rate variability in the 19-year-old offspring
}

\author{
Dorte Rytter $^{1 *}$, Jeppe H. Christensen ${ }^{2}$, Bodil H. Bech ${ }^{1}$, Erik B. Schmidt ${ }^{3}$, Tine B. Henriksen ${ }^{4}$ and \\ Sjurdur F. Olsen ${ }^{5}$ \\ ${ }^{1}$ Section for Epidemiology, Department of Public Health, Aarbus University, Bartholins Allé 2, DK-8000 Aarbus C, Denmark \\ ${ }^{2}$ Department of Nephrology and Center for Cardiovascular Disease, Aalborg Hospital, Aarhus University Hospital, Aalborg, \\ Denmark \\ ${ }^{3}$ Department of Cardiology and Center for Cardiovascular Disease, Aalborg Hospital, Aarhus University Hospital, Aalborg, \\ Denmark \\ ${ }^{4}$ Department of Pediatrics, Skejby Hospital, Aarhus University Hospital, Aarhus, Denmark \\ ${ }^{5}$ Centre for Fetal Programming, Statens Serum Institut, Amager, Denmark \\ (Submitted 19 May 2011 - Final revision received 9 November 2011 - Accepted 10 November 2011 - First published online 7 February 2012)
}

\section{Abstract}

Studies in experimental animals and human subjects have suggested that intake of $n-3$ fatty acids in early life can affect cardiovascular risk factors in adult life. Therefore, the aim of the present study was to investigate the effect of fish oil (FO) supplementation during the third trimester of pregnancy on blood pressure (BP), heart rate (HR) and HR variability (HRV) in the 19-year-old offspring. The study was based on follow-up of a randomised, controlled trial from 1990, in which 533 pregnant women were randomised to FO, olive oil (OO) or no oil (NO) during the last trimester of pregnancy. The offspring was invited to a physical examination including BP, HR and HRV measurements. A subgroup consisting of the offspring of mothers with a low baseline fish intake also had $24 \mathrm{~h}$ HRV determined. The OO group was used as reference and multiple linear regression modelling was used to compare the FO and OO groups. A total of 180 of the offspring from the FO and $\mathrm{OO}$ groups agreed to participate in the study (45\%). The adjusted difference between the FO and OO groups was 2 (95\% $\mathrm{CI}-1,4) \mathrm{mmHg}$ in systolic and $1(95 \% \mathrm{CI} 0,3) \mathrm{mmHg}$ in diastolic BP. The difference in HR was 1 (95\% CI - 2, 4). Also, HRV indices did not differ significantly between groups. Hence, FO supplementation during late pregnancy was not associated with offspring BP, HR and HRV during adolescence.

\section{Key words: Blood pressure: Heart rate variability: Fish oil: Developmental programming}

Fish consumption may reduce the risk of $\mathrm{CVD}^{(1,2)}$. This is believed to be due to the content in fish of $n$ - 3 long-chain PUFA, in particular EPA and DHA, although other components in fish, like vitamin $\mathrm{D}, \mathrm{I}, \mathrm{Se}$ and proteins may also be beneficial $^{(3)}$. Protection against CVD is most probably multifactorial. Fish consumption and fish oil (FO) supplementation have been associated with a decrease in blood pressure (BP), particularly in subjects with a high $\mathrm{BP}^{(4,5)}$. Likewise, heart rate (HR) is negatively associated with long-chain $n$-3 PUFA intake ${ }^{(6)}$. FO has also been found to be associated with increased HR variability (HRV), both in different patient populations and in healthy subjects ${ }^{(7-9)}$. A low HRV has been found to be associated with an increased risk of sudden cardiac death ${ }^{(10)}$

The programming theory proposes that an unsuitable environment at critical or sensitive periods of development might result in long-term changes in the structure and function of the organism and thereby increase the risk of developing various diseases such as CVD ${ }^{(11)}$.

During fetal life, long-chain $n$-3 PUFA, and in particular DHA, is transferred to the fetus from the mother via the placenta $^{(12)}$. Major deposition of long-chain $n-3$ PUFA takes place in the fetal brain during late pregnancy ${ }^{(12)}$, and it is therefore possible that long-chain $n$-3 PUFA supplementation during pregnancy could have long-term effects on the

Abbreviations: BP, blood pressure; bpm, beats per min; $\mathrm{FO}$, fish oil; $\mathrm{HR}$, heart rate; $\mathrm{HR}_{\mathrm{BP}}$, resting heart rate; $\mathrm{HR}_{\mathrm{E} / \mathrm{I}}$, ratio between heart rate during inhalation and exhalation; HRV, heart rate variability; NO, no oil; OO, olive oil.

*Corresponding author: D. Rytter, fax +45 8613 1580, email dr@soci.au.dk 
neuronal control of BP in the offspring. This hypothesis has been addressed in a study with rats where a low intake of non-marine $n-3$ PUFA ( $\alpha$-linolenic acid) during pregnancy increased the mean arterial $\mathrm{BP}$ in the adult offspring ${ }^{(13,14)}$

The incorporation of long-chain $n$ - 3 PUFA in synaptic membranes could also potentially influence the autonomic control of HR. The progressive maturation of the autonomic nervous system during fetal life and infancy ${ }^{(15)}$ renders this period a sensitive time, during which nutritional influences may exert long-term effects on vagal tone and hence HR, HRV and BP.

Short-term effects of FO supplementation on BP and HRV have been shown in infants ${ }^{(16,17)}$, but the evidence for a possible programming effect of long-chain $n$-3 PUFA on later cardiovascular health in humans is sparse and inconclusive ${ }^{(18-21)}$.
The present study is a follow-up of a randomised, controlled trial from 1990 where pregnant women were randomised to FO supplementation, olive oil (OO) or no oil (NO) during the last trimester of pregnancy ${ }^{(22)}$. The objective was to test the hypothesis that maternal intake of long-chain $n-3$ PUFA during pregnancy influences BP, HR and HRV in the offspring.

\section{Methods}

\section{Original study population}

The aim of the original study was to investigate the effect of FO supplementation on gestational length. The recruitment

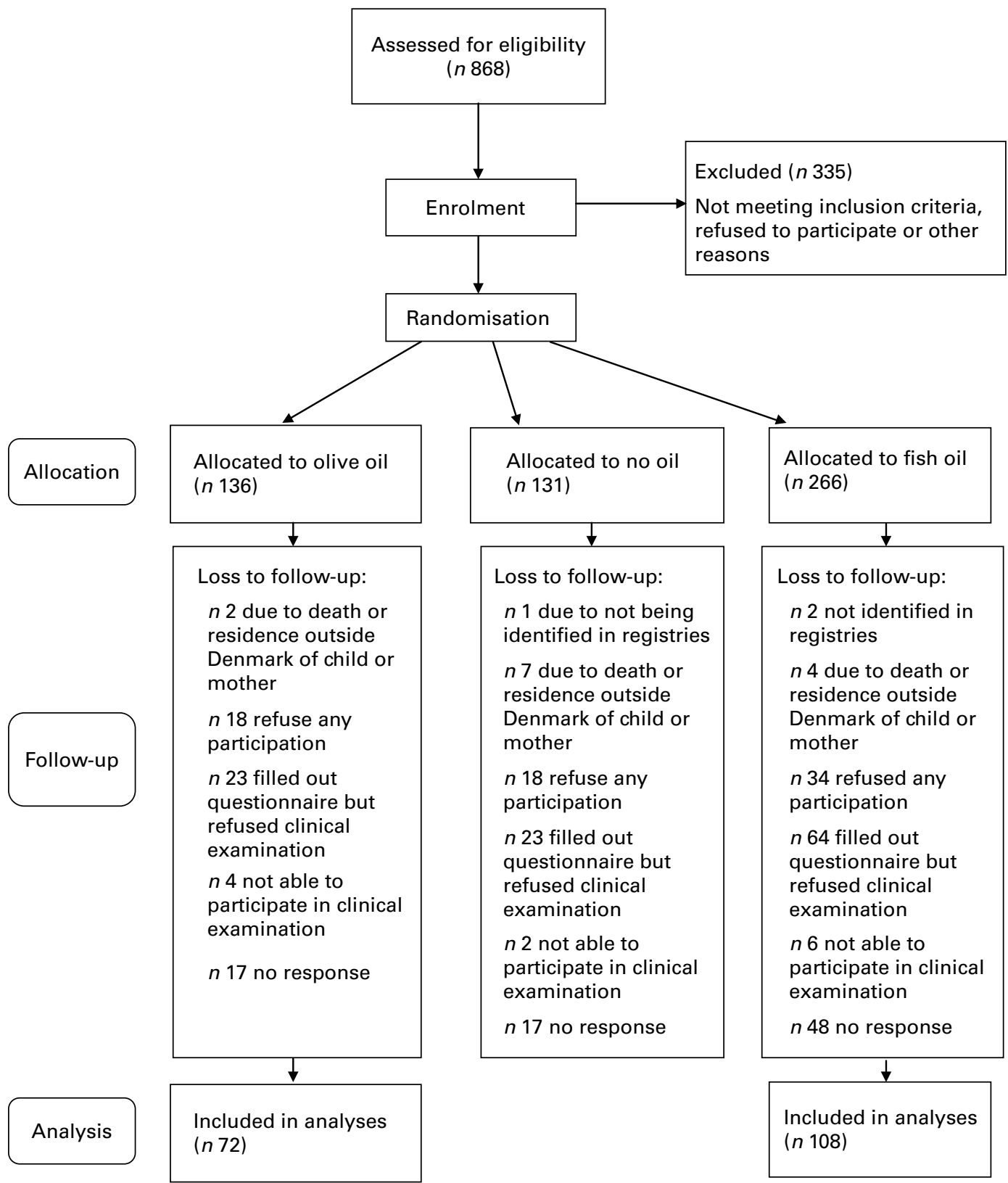

Fig. 1. A 19-year follow-up of the offspring from a randomised controlled trial with fish oil supplementation during pregnancy ${ }^{(22)}$. 
and randomisation of the original study population have previously been described in detail ${ }^{(22)}$.

Briefly, 533 women in gestational week 30 who attended the antenatal clinic in Aarhus, Denmark, were randomised to FO capsules ( $2.7 \mathrm{~g}$ long-chain $n$-3 PUFA/d; $n$ 266), or similar capsules with OO ( $n$ 136) or NO capsules ( $n$ 131) in 1990. The supplement was given until delivery. The women were blinded for study interventions and the capsules and boxes looked identical. The pregnant women filled out a simple FFQ in order to assess their baseline fish consumption. After delivery, all women received a form concerning information on compliance and side effects. Those women, who returned the form, were informed about their study allocation. Hence at the time of the follow-up study, most women were unblinded for study allocation.

The offspring from this randomised, controlled trial constituted the study population in the present study. At the time of this study, the offspring were aged between 18 and 19 years. A total of 517 (97\%) mother-and-child pairs were alive and living in Denmark.

All the mothers were contacted by postal mail and asked to hand over an invitation to the children asking them to complete a self-administered, web-based questionnaire concerning anthropometric measures and lifestyle. The children were also asked to participate in a physical examination. A total of 382 agreed to fill out the questionnaire and 243 agreed to participate in the clinical examination. The participation rates in the physical examination differed between randomisation groups, being lower in the FO group (41\%) compared with the OO group (53\%; Fig. 1).

At the physical examination, short-term (2 min) HRV was measured in horizontal position following $5 \mathrm{~min}$ of rest using a validated handheld device (HealthMate, Medicus Engineering) ${ }^{(23,24)}$. The standard deviation of the RR intervals (time intervals between consecutive heart beats) $\left(\mathrm{SDNN}_{2 \mathrm{~min}}\right)$ was determined. Following this, resting $\mathrm{BP}$ and $\mathrm{HR}\left(\mathrm{HR}_{\mathrm{BP}}\right)$ was measured three times (with a 2 min interval) also in horizontal position with an automatic BP device (OMRON M6 Comfort (HEM-7000-E)). The mean systolic and diastolic BP as well as the HR of the last two measurements were used in the analyses. Finally, as a measure of the function of the parasympathetic nervous system, the median ratio between the highest and the lowest HR within a breathing cycle $\left(\mathrm{HR}_{\mathrm{E} / \mathrm{I}}\right)$ was measured, with the participant sitting at a desk holding the HealthMate in both hands. The participant was instructed to breathe slowly for 1 min according to an illustration on the HealthMate display. The two assistants, who made all the measurements, were blinded to group allocation.

The largest effect of FO supplementation would a priori be expected among offspring from mothers with a low baseline fish intake. A total of forty-six (44\%) offspring of mothers with a low baseline fish intake agreed to participate in the physical examination. These participants had undertaken an extended physical examination. This included a $24 \mathrm{~h}$ Holter recording, measured using a two-channel digital recorder with a sampling rate of $1024 \mathrm{~Hz}$ (Lifecard CF; Spacelabs Healthcare) and analysed using Cardionavigator Plus Impressarioa Symphony (also from Spacelabs Healthcare). The time domain HRV indices RR, SDNN, SDNNindex, SDANNindex, RMSSD and PNN50 (for description, see Table 1) were obtained. Each QRS complex was classified as normal sinus rhythm, atrial or ventricular premature, artifact or unclassified. Abnormal QRS complexes were excluded in the HRV analysis, and the recordings were processed without knowledge of the group allocation. Data were gathered while the participants continued their daily activities, the only restrictions being not to bathe and not to partake in sports involving physical contact.

This study was conducted according to the guidelines laid down in the Declaration of Helsinki and all procedures involving human subjects were approved by the local ethics committee (case no. M-ÅA 20060182) and the Danish Data Protection Agency (journal no. 2006-41-6257). Written informed consent was obtained from all subjects.

\section{Statistical analyses}

The OO group was used as the reference for the following reasons: (1) the original study showed that blinding worked well in the OO group, indicating that this group was unlikely to have increased their fish consumption during the trial period. The NO group, on the other hand, was unblinded and could potentially have increased their long-chain n-3 PUFA intake during the trial period. Therefore, this group was not included in the present comparison. (2) It seems reasonable to assume that $\mathrm{OO}$ in the supplemented amounts was inert.

Blinding of study allocation during data analysis was not possible due to the different numbers of participants in the FO and OO groups

The distribution of short-term HRV variables was skewed and the data were log-transformed before analyses.

Multiple linear regression modelling, adjusting for sex and smoking, was used to estimate the effect of $\mathrm{FO}$ relative to OO supplementation on BP, HR and HRV indices. Additionally, diastolic and systolic BP was adjusted for maternal systolic and diastolic BP in week 30 of gestation, respectively, and $\mathrm{HR}_{\mathrm{BP}}$ was adjusted for maternal $\mathrm{HR}$ in week 30 of gestation.

Table 1. Description of the time domain heart rate variability (HRV) variables used in the study

\begin{tabular}{ll}
\hline HRV variable & Description \\
\hline RR (ms) & Mean of all normal time intervals between \\
& consecutive heart beats in the 24h recording \\
SDNN (ms) & Standard deviation of all normal RR intervals \\
in the $24 \mathrm{~h}$ or 2 min recordings \\
SDNNindex (ms) & Mean of the standard deviation of all normal \\
& RR intervals for all 5 min segments in the \\
SDANN (ms) & $24 \mathrm{~h}$ recording \\
& Standard deviation of the mean of all normal \\
& RR intervals measured in successive \\
RMSSD (ms) & 5 min intervals \\
& The square root of the mean of the sum of \\
PNN50 (\%) & squares of differences between adjacent \\
& RR intervals in the $24 \mathrm{~h}$ recording \\
HR & Percentage of successive RR interval \\
& differences $>50$ ms during the $24 \mathrm{~h}$ recording \\
& Median ratio between the highest and the \\
& lowest HR within every breathing cycle in a \\
& 1 min recording
\end{tabular}


Table 2. Characteristics of participants and non-participants

(Number of participants and percentages; mean values and standard deviations; medians and interquartile ranges)

\begin{tabular}{|c|c|c|c|c|c|}
\hline & \multicolumn{2}{|c|}{ Participants } & \multicolumn{2}{|c|}{ Non-participants } & \multirow[b]{2}{*}{$P$} \\
\hline & $n^{\star}$ & $\%$ & $n^{\star}$ & $\%$ & \\
\hline \multicolumn{6}{|l|}{ Mothert } \\
\hline Parity $\ddagger$ & 180 & & 214 & & 0.83 \\
\hline 0 & & 59.4 & & 59.4 & \\
\hline 1 & & $31 \cdot 1$ & & $29 \cdot 4$ & \\
\hline$>2$ & & 9.4 & & $11 \cdot 2$ & \\
\hline Age at giving birth (years)§ & 180 & & 214 & & 0.09 \\
\hline Mean & \multirow{2}{*}{\multicolumn{2}{|c|}{$\begin{array}{c}29.9 \\
4.5\end{array}$}} & \multicolumn{2}{|c|}{$29 \cdot 2$} & \\
\hline $\begin{array}{l}\text { SD } \\
\text { Smoking (yes) }\end{array}$ & & & & & \\
\hline Smoking (yes)‡ & 180 & $25 \cdot 6$ & 213 & $33 \cdot 3$ & 0.09 \\
\hline Pre-pregnancy BMI $\left(\mathrm{kg} / \mathrm{m}^{2}\right) \|$ & 173 & & 200 & & 0.05 \\
\hline Median & \multirow{2}{*}{\multicolumn{2}{|c|}{$\begin{array}{c}20 \cdot 8 \\
19 \cdot 7-22 \cdot 6\end{array}$}} & \multirow{2}{*}{\multicolumn{2}{|c|}{$\begin{array}{c}21 \cdot 3 \\
20 \cdot 1-23 \cdot 2\end{array}$}} & \\
\hline Interquartile range & & & & & \\
\hline Systolic BP (mmHg)§ף & 179 & & \multirow{2}{*}{\multicolumn{2}{|c|}{124}} & 0.93 \\
\hline Mean & \multicolumn{2}{|c|}{124} & & & \\
\hline SD & \multicolumn{2}{|c|}{15} & \multicolumn{2}{|c|}{15} & \\
\hline Diastolic BP $(\mathrm{mmHg}) \S \rrbracket$ & 179 & & 214 & & 0.63 \\
\hline Mean & \multirow{2}{*}{\multicolumn{2}{|c|}{$\begin{array}{c}69 \\
9\end{array}$}} & \multicolumn{2}{|c|}{69} & \\
\hline SD & & \multirow[t]{2}{*}{9} & \multirow{2}{*}{\multicolumn{2}{|c|}{9}} & \\
\hline Resting heart rate $(\mathrm{bpm}) \S \rrbracket$ & 176 & & 209 & & 0.57 \\
\hline Mean & \multicolumn{2}{|c|}{86} & & & \\
\hline SD & & & & & \\
\hline Fish intakeł & 180 & & 214 & & 0.79 \\
\hline Low & & $20 \cdot 6$ & & $20 \cdot 6$ & \\
\hline Medium & & $56 \cdot 1$ & & $58 \cdot 9$ & \\
\hline High & & 23.3 & & $20 \cdot 6$ & \\
\hline Offspring (19 years)** & & & & & \\
\hline Female & & 53.9 & & $34 \cdot 6$ & $<0.001$ \\
\hline Smoking $\ddagger$ & 174 & & 108 & & 0.81 \\
\hline Current & & $18 \cdot 4$ & & $20 \cdot 4$ & \\
\hline Ex-smoker & & 4.0 & & $4 \cdot 6$ & \\
\hline Occasional smoker & & $21 \cdot 3$ & & $16 \cdot 7$ & \\
\hline Never smoker & & $56 \cdot 3$ & & $58 \cdot 3$ & \\
\hline Fish hot mealł & 176 & & 105 & & 0.54 \\
\hline Never & & 15.9 & & $12 \cdot 4$ & \\
\hline $1-2$ per month & & $43 \cdot 2$ & & $38 \cdot 1$ & \\
\hline $3-4$ per month & & $30 \cdot 1$ & & $35 \cdot 2$ & \\
\hline$>5$ per month & & $10 \cdot 8$ & & $14 \cdot 3$ & \\
\hline Fish cold mealł & 175 & & 101 & & 0.41 \\
\hline Never & & $19 \cdot 4$ & & $27 \cdot 7$ & \\
\hline $1-2$ per month & & 39.4 & & 37.6 & \\
\hline 3-4 per month & & $17 \cdot 1$ & & $15 \cdot 8$ & \\
\hline$>5$ per month & & $24 \cdot 0$ & & $18 \cdot 8$ & \\
\hline Exerciseł & 180 & $76 \cdot 7$ & 113 & $68 \cdot 1$ & 0.11 \\
\hline Strenuous exercise $\neq, \dagger \dagger$ & 170 & $60 \cdot 0$ & 107 & 58.9 & 0.85 \\
\hline 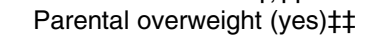 & & & & & \\
\hline Motherł & 168 & 15.5 & 111 & $19 \cdot 8$ & 0.35 \\
\hline Father $\ddagger$ & 170 & $18 \cdot 8$ & 99 & $23 \cdot 2$ & 0.39 \\
\hline Mother or father $\ddagger$ & 168 & 30.4 & 102 & 34.3 & 0.50 \\
\hline Self-reported BMI $\left(\mathrm{kg} / \mathrm{m}^{2}\right) \S$ & 179 & & 113 & & 0.60 \\
\hline Mean & & & & & \\
\hline SD & & & & & \\
\hline Birth weight $(\mathrm{g}) \S$ & 180 & & 214 & & 0.02 \\
\hline Mean & & & & & \\
\hline SD & & & & & \\
\hline Gestational age (d)\| & 180 & & 214 & & $0.37 \ddagger$ \\
\hline Median & & & & & \\
\hline
\end{tabular}

$\mathrm{BP}$, blood pressure; bpm, beats per min.

* Number of participants or non-participants with information on the different covariates.

† Information collected from a self-administered questionnaire to the pregnant women in week 16 of gestation.

$\ddagger \chi^{2}$ test.

$\S$ Student's $t$ test.

W Wilcoxon rank sum test.

१ Measured in week 30 of gestation.

${ }^{* *}$ Information collected from a self-administered, web-based questionnaire to the offspring at the age of $18-19$ years. Sex and birth weight collected from medical records.

t† Defined as exercise of at least 20 min duration, resulting in breathlessness.

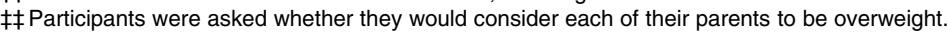


Information on smoking was collected from the web-based questionnaire. The participants were asked whether they were current, ex-, occasional or never smokers. Maternal BP and HR were measured at the antenatal clinic by one investigator in week 30 of gestation (before FO supplementation). It was measured in the right arm after at least $10 \mathrm{~min}$ of rest in a

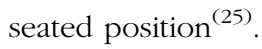

Since there were indications of differences in offspring fish intake and exercise pattern, additional analyses of the effect of FO supplementation on BP, HR and short-term HRV were performed, adjusting for current fish intake and exercise pattern.

Also, additional analyses were done for BP, adjusting for offspring height and weight. This was left out of the primary analyses, since the potential effect of FO supplementation could be mediated through effects on height and weight ${ }^{(26)}$. Hence if this was the case, a potential association between FO and $\mathrm{BP}$ would be reduced upon adjustment.

Differential programming effects may be found in boys and girls $^{(20,26)}$, and therefore all analyses, except those for $24 \mathrm{~h}$ HRV indices, were also stratified for sex. The $24 \mathrm{~h} \mathrm{HRV} \mathrm{indices}$ held too few participants to stratify. The multiple regression analyses for BP and short-term HRV indices were also stratified for the mothers' baseline fish intake.

Sensitivity analyses were made for systolic and diastolic BP imputing either the 10th or the 90th percentile for missing values. For systolic BP, the 10th and 90th percentiles were 97 and $120 \mathrm{mmHg}$, respectively, whereas for diastolic BP they were 57 and $71 \mathrm{mmHg}$, respectively.

A $P$ value $<0.05$ was considered statistically significant.

All statistical tests were performed using STATA software package 11.0 (Stata Corporation).

\section{Results}

\section{Participants}

Characteristics related to $\mathrm{BP}$, pregnancy and birth of participants and non-participants are given in Table 2. Characteristics of the mothers were collected from the interview and questionnaire during pregnancy, whereas characteristics of the offspring were collected from the questionnaire at 18-19 years of age. Therefore, we only had information regarding covariates for the offspring who filled out the questionnaire ( $n$ 293). The participants differed significantly from the non-participants with regard to sex and birth weight. Also, participants tended to do more exercise compared to non-participants and to have older mothers and mothers with a lower pre-pregnancy BMI. Mothers of participants and non-participants did not differ with respect to BP and HR in week 30 of gestation. This was also the case after stratification for the randomisation group (data not shown).

A description of the participants in the two randomisation groups is given in Table 3. Both groups were similar with respect to most characteristics. However, smoking was more prevalent among participants from the OO group compared to the FO group, and mothers' systolic $\mathrm{BP}$ was higher in the OO group compared to the FO group. Also, there was a tendency towards more participants in the FO group doing exercise, particularly among females and offspring from the FO group who tended to eat more fish.

The subjects in the present study were generally healthy. The median systolic and diastolic BP in males was 114 and $63 \mathrm{mmHg}$, respectively. Overall, $18 \cdot 1 \%$ of the males had a systolic BP above $120 \mathrm{mmHg}$, whereas only $1 \%$ had a diastolic BP above $80 \mathrm{mmHg}$. Among the females, median systolic and diastolic BP were 104 and $64 \mathrm{mmHg}$, respectively; with $2 \%$ having a systolic BP above $120 \mathrm{mmHg}$, and $1 \%$ having a diastolic BP above $80 \mathrm{mmHg}$. Median resting $\mathrm{HR}$ was 54

Table 3. Characteristics of mothers and offspring participating in the 19-year follow-up study according to randomisation groups*

(Percentages, mean values and standard deviations; medians and interquartile ranges)

\begin{tabular}{|c|c|c|c|c|}
\hline \multirow[b]{2}{*}{ Group } & \multicolumn{2}{|c|}{$\mathrm{OO}(n 72)$} & \multicolumn{2}{|c|}{ FO $(n 108)$} \\
\hline & Mean & SD & Mean & SD \\
\hline \multicolumn{5}{|l|}{ Mothert } \\
\hline \multicolumn{5}{|l|}{ Parity (\%) } \\
\hline 0 & \multicolumn{2}{|c|}{$58 \cdot 3$} & \multicolumn{2}{|c|}{$60 \cdot 2$} \\
\hline 1 & \multicolumn{2}{|c|}{$33 \cdot 3$} & \multicolumn{2}{|c|}{$29 \cdot 6$} \\
\hline$>2$ & \multicolumn{2}{|c|}{$8 \cdot 3$} & \multicolumn{2}{|c|}{$10 \cdot 2$} \\
\hline Age at birth (years) & $30 \cdot 0$ & $4 \cdot 3$ & $29 \cdot 9$ & 4.6 \\
\hline Smokers (yes; \%) & \multicolumn{2}{|c|}{$25 \cdot 0$} & \multicolumn{2}{|c|}{25.9} \\
\hline \multicolumn{5}{|l|}{ Pre-pregnancy BMI $\left(\mathrm{kg} / \mathrm{m}^{2}\right)$} \\
\hline Median & \multirow{2}{*}{\multicolumn{2}{|c|}{$\begin{array}{c}20 \cdot 6 \\
19 \cdot 3-22 \cdot 9\end{array}$}} & \multirow{2}{*}{\multicolumn{2}{|c|}{$\begin{array}{c}20 \cdot 9 \\
19 \cdot 8-22 \cdot 2\end{array}$}} \\
\hline Interquartile range & & & & \\
\hline Systolic BP $(\mathrm{mmHg}) \ddagger$ & 127 & 16 & 122 & 14 \\
\hline Diastolic BP $(\mathrm{mmHg}) \ddagger$ & 69 & 8 & 69 & 9 \\
\hline Resting heart rateł & 86 & 11 & 85 & 12 \\
\hline \multicolumn{5}{|l|}{ Offspring§ } \\
\hline Female (\%) & \multicolumn{2}{|c|}{$48 \cdot 6$} & \multicolumn{2}{|c|}{57.4} \\
\hline \multicolumn{5}{|l|}{ Smokers (\%) } \\
\hline Current & \multicolumn{2}{|c|}{$27 \cdot 1$} & \multicolumn{2}{|c|}{$12 \cdot 5$} \\
\hline Ex-smoker & \multicolumn{2}{|c|}{$\begin{array}{c}8.6 \\
11.3\end{array}$} & \multirow{2}{*}{\multicolumn{2}{|c|}{$\begin{array}{c}1.0 \\
26.0\end{array}$}} \\
\hline Occasional smoker & \multirow{2}{*}{\multicolumn{2}{|c|}{$\begin{array}{l}14 \cdot 3 \\
50 \cdot 0\end{array}$}} & & \\
\hline Never smoker & & & \multicolumn{2}{|c|}{$60 \cdot 6$} \\
\hline Fish hot meal (\%) & & & & \\
\hline Never & & & & \\
\hline $1-2$ per month & & & & \\
\hline $3-5$ per month & & & & \\
\hline$>5$ a month & & & & \\
\hline Fish cold meal (\%) & & & & \\
\hline Never & & & & \\
\hline $1-2$ per month & & & & \\
\hline $3-5$ per month & & & & \\
\hline$>5$ per month & & & & \\
\hline Exercise (yes) & & & & \\
\hline Strenuous exercise (yes)\| & & & & \\
\hline Parental overweight (\%) & & & & \\
\hline Mother & & & & \\
\hline Father & & & & \\
\hline Mother or father & & & & \\
\hline Birth weight (g) & 3543 & 489 & 3642 & 489 \\
\hline Gestational age (d) $\dagger$ & & & & \\
\hline Median & & & & \\
\hline Interquartile ranges & 277 & & & \\
\hline
\end{tabular}

OO, olive oil; FO, fish oil; BP, blood pressure.

*Previously published by Rytter et al. ${ }^{(32,33)}$.

†Information collected from a self-administered questionnaire to the pregnant women in week 16 of gestation.

$\ddagger$ Measured in week 30 of gestation

§Information collected from a self-administered web-based questionnaire to the offspring at the age of 18-19 years. Sex and birth weight collected from medical records.

\| Defined as exercise of at least 20 min duration, resulting in breathlessness.

I Participants were asked whether they would consider each of their parents to be overweight. 
Table 4. Blood pressure (BP) and resting heart rate $\left(\mathrm{HR}_{\mathrm{BP}}\right)$ for the three randomisation groups

(Mean values and standard deviations; differences and $95 \%$ confidence intervals)

\begin{tabular}{|c|c|c|c|c|c|c|c|c|c|c|c|c|c|}
\hline & \multirow[b]{2}{*}{$n$} & \multicolumn{4}{|c|}{ Systolic BP $(\mathrm{mmHg})$} & \multicolumn{4}{|c|}{ Diastolic BP (mmHg) } & \multicolumn{4}{|c|}{$\mathrm{HR}_{\mathrm{BP}}(\mathrm{bpm})$} \\
\hline & & Mean & SD & Difference* & $95 \% \mathrm{Cl}$ & Mean & SD & Difference† & $95 \% \mathrm{Cl}$ & Mean & SD & Differenceł & $95 \% \mathrm{Cl}$ \\
\hline OO & 72 & 109 & 10 & Reference & - & 63 & 6 & Reference & - & 58 & 9 & Reference & - \\
\hline FO & 108 & 109 & 10 & 2 & $-1,4$ & 64 & 6 & 1 & 0,3 & 59 & 9 & 1 & $-2,4$ \\
\hline
\end{tabular}

bpm, Beats per min; OO, olive oil; FO, fish oil.

* Difference relative to OO, adjusted for sex, offspring smoking and maternal systolic BP in week 30 of gestation.

†Difference relative to OO, adjusted for sex, offspring smoking and maternal diastolic BP in week 30 of gestation.

$\ddagger$ Difference relative to $\mathrm{OO}$, adjusted for sex, offspring smoking and maternal heart rate in week 30 of gestation.

(interquartile range 51-62) beats per $\min (\mathrm{bpm})$ for males and 60 (interquartile range 54-66) bpm for females.

\section{Blood pressure and resting heart rate}

Mean diastolic and systolic $\mathrm{BP}$ as well as $\mathrm{HR}_{\mathrm{BP}}$ are presented in Table 4. We found no difference in BP between the FO group and the OO group. Additional adjustment for offspring exercise and current fish intake did not change estimates (not shown). The same was the case when adjustment was made for height and weight (not shown). The sensitivity analyses for systolic BP also did not change estimates. The estimated difference in diastolic BP, however, tended to be somewhat sensitive to imputation of the 90th percentile for missing values (difference 2 (95\% CI 0, 3) $\mathrm{mmHg} ; P=0 \cdot 018)$. Stratification by sex did not influence the results (data not shown). This was also the case after further adjustment for offspring exercise pattern and current fish intake. Finally, stratification by mother's baseline fish intake did not change estimates significantly (data not shown). There was no significant difference between FO supplementation relative to $\mathrm{OO}$ in resting $\mathrm{HR}$ (Table 4), independent of mother's baseline fish intake. Stratification for sex indicated no difference for either sex, independent of further adjustments (data not shown).

\section{Short-term heart rate variability}

Mean 2 min SDNN and $\mathrm{HR}_{\mathrm{E} / \mathrm{I}}$ are shown in Table 5. There was no difference in short-term HRV indices between the FO and OO groups. Similar findings were observed when the analyses were stratified by sex (data not shown). Upon stratification for mother's baseline fish intake, a statistically significant effect of FO supplementation was observed on $\mathrm{HR}_{\mathrm{E} / \mathrm{I}}$ among offspring of women with a high baseline fish intake (7 (95\% CI 1, 14)\%; $P=0.03)$.

$\mathrm{SDNN}_{2 \text { min }}$ tended to correlate significantly with SDNN $(P=0.07)$. However, the correlation only became significant after adjustment for sex $(P=0 \cdot 04)$.

\section{$24 \mathrm{~h}$ heart rate variability indices}

Data for the $24 \mathrm{~h} \mathrm{HRV}$ indices are presented in Table 6. No statistically significant effect of FO supplementation was observed for any of the $24 \mathrm{~h} \mathrm{HRV}$ indices. $\mathrm{HR}_{24}$ tended to be lower in the FO group compared with the OO group, but the difference was mainly caused by a single participant in the OO group, with a high mean HR during the night (128 bpm). According to the questionnaire data, this participant had a high intake of alcohol and a drug abuse, which potentially could explain the high HR during night time. When this participant was left out of the analyses, the difference between the $\mathrm{OO}$ and $\mathrm{FO}$ groups decreased from -5 $(95 \% \mathrm{CI}-12,2)$ to $-3(95 \% \mathrm{CI} 10,3) \mathrm{bpm}(P=0 \cdot 3)$.

\section{Discussion}

Maternal supplementation with FO or OO during the last trimester of pregnancy did not cause any significantly different values for BP, HR or HRV in the 19-year-old offspring. Furthermore, no differences were observed when the data were stratified by sex. Stratification for maternal baseline fish intake also did not influence most estimates. However, a positive effect of $\mathrm{FO}$ supplementation was seen on $\mathrm{HR}_{\mathrm{E} / \mathrm{I}}$ among offspring of mothers with a high baseline fish intake.

There was a rather large loss to follow-up in the study, which could potentially have influenced the results, due to

Table 5. Short-term heart rate variability (HRV) for the two randomisation groups

(Geometric means, interquartile ranges, percentage of differences and $95 \%$ confidence intervals)

\begin{tabular}{|c|c|c|c|c|c|c|c|c|c|}
\hline & \multirow[b]{2}{*}{$n$} & \multicolumn{4}{|c|}{$\mathrm{SDNN}_{2 \min }$} & \multicolumn{4}{|c|}{$H R_{E / I}$} \\
\hline & & $\begin{array}{l}\text { Geometric } \\
\text { mean (ms) }\end{array}$ & $\begin{array}{c}\text { Interquartile } \\
\text { range (ms) }\end{array}$ & Difference $(\%)^{*}$ & $95 \% \mathrm{Cl}(\%)$ & $\begin{array}{l}\text { Geometric } \\
\text { mean (ms) }\end{array}$ & $\begin{array}{l}\text { Interquartile } \\
\text { range (ms) }\end{array}$ & Difference $(\%)^{\star}$ & $95 \% \mathrm{Cl}(\%)$ \\
\hline $\mathrm{OO}$ & 72 & 65 & $43-99$ & Reference & - & 1.41 & $1 \cdot 31-1 \cdot 49$ & Reference & - \\
\hline $\mathrm{FO}$ & 108 & 68 & $46-97$ & 5 & $-12,25$ & 1.42 & $1.32-1.50$ & 1 & $-3,5$ \\
\hline
\end{tabular}

$\mathrm{SDNN}_{2 \min }$, standard deviation of the RR intervals in a 2 min heart rate recording; $\mathrm{HR}_{\mathrm{E} / \mathrm{l}}$, ratio between the highest and the lowest heart rate within each breathing cycle in a 1 min recording; OO, olive oil; FO, fish oil.

* Difference (\%) relative to OO, adjusted for sex and offspring smoking. 
Table 6. $24 \mathrm{~h}$ Heart rate $(\mathrm{HR})$ variability variables for the olive oil $(\mathrm{OO})$ and fish oil $(\mathrm{FO})$ groups $\dagger$

(Mean values and standard deviations; differences and $95 \%$ confidence intervals)

\begin{tabular}{|c|c|c|c|c|c|c|c|}
\hline Group & SDNN (ms) & $\mathrm{RR}(\mathrm{ms})$ & $\mathrm{HR}(\mathrm{ms})$ & SDNNindex (ms) & SDANN (ms) & RMMSD (ms) & PNN50 (\%) \\
\hline \multicolumn{8}{|l|}{$\mathrm{OO}(n 13)$} \\
\hline Mean & 184 & 746 & 87 & 65 & 170 & 56 & $18 \cdot 1$ \\
\hline $\mathrm{SD}$ & 45 & 75 & 9 & 26 & 40 & 31 & $12 \cdot 8$ \\
\hline Difference & Reference & Reference & Reference & Reference & Reference & Reference & Reference \\
\hline \multicolumn{8}{|l|}{$\mathrm{FO}(n 24)$} \\
\hline Mean & 193 & 792 & 82 & 67 & 176 & 56 & $20 \cdot 5$ \\
\hline SD & 40 & 76 & 8 & 19 & 39 & 20 & 9.9 \\
\hline Difference* & 4 & 46 & -5 & 2 & 0 & 0 & 3.1 \\
\hline $95 \% \mathrm{Cl}$ & $-32,40$ & $-19,112$ & $-12,2$ & $-16,20$ & $-33,34$ & $-20,20$ & $-5 \cdot 8,12 \cdot 1$ \\
\hline
\end{tabular}

* Difference relative to $\mathrm{OO}$, adjusted for sex and offspring smoking.

†For a description of the variables, see Table 1.

the possibility of a statistical type 2 error. Hence, with the obtained participation rates we would be able to detect an overall difference in systolic and diastolic BP of approximately 4 and $3 \mathrm{mmHg}$, respectively, and a difference in HR of 4 with a power of $80 \%$ and significance level of 0.05 . With regard to the short-term HRV variables $\mathrm{SDNN}_{2 \text { min }}$ and $\mathrm{HR}_{\mathrm{E} / \mathrm{I}}$, we had the power to detect differences of 25 and $5 \%$, respectively. For the subgroup analyses, the differences should have been even larger to be detected. Previous studies on the programming of BP by early long-chain $n$-3 PUFA supplementation ${ }^{(5)}$ have found differences in systolic $\mathrm{BP}$ in the range of $2-3 \mathrm{mmHg}$ and in diastolic BP between 1 and $3 \mathrm{mmHg}$, indicating that the present study could have been underpowered to detect small differences. However, in spite of the low power, the size of the estimated difference in BP and HR did not indicate any clinically relevant effect of early longchain n-3 PUFA supplementation. Moreover, although the participation rate was low, the present study is one of the largest studies to date. Hence, this does not explain the discrepancy between the findings from this study compared with other studies demonstrating an association between early long-chain $n$-3 PUFA supplementation and later BP.

If participation was associated with the outcome, this could have introduced bias of the estimate. Sensitivity analysis for BP showed that diastolic BP was somewhat sensitive to imputation of the 90th percentile for missing values, indicating that the results could be biased. However, maternal BP was the same among participants and non-participants, indicating that the estimates were not biased due to an association between participation and a disposition for high BP. Hence, it seems unlikely that non-participants should have had a diastolic BP this high. According to the questionnaire data, participation was also not associated with BMI (Table 2).

The unblinding of study participants is also not likely to have affected the results, since all outcomes were clinically measured by assistants who were blinded for study allocation. There is also no reason to believe that the reporting of confounders should be affected by oil allocation during pregnancy.

Compliance was significantly higher among participants from the FO group compared to non-participants. By primarily including participants with a high compliance in the study, this would have served to strengthen any possible association between FO supplementation and later BP, HR and HRV. Hence, this cannot explain the negative findings of the present study.

To our knowledge, no previous study involving human subjects has examined the effect of FO supplementation during pregnancy on offspring BP later in life. Studies in rats, however, have shown that $n$-3 PUFA deficiency during fetal and early postnatal life increases BP in adulthood ${ }^{(13,14)}$.

The timing of FO supplementation could be of importance. Long-chain $n$-3 PUFA is primarily accumulated in the fetal brain from the third trimester of pregnancy through the first year of life. Hence, an effect of FO supplementation would be expected to have the largest effect during this period of time. A number of human studies have investigated the possible programming effect of FO during early infancy on BP later in life, with inconsistent results. Thus, in a Danish study, breast-feeding women with a baseline fish intake below the population median were randomised to $\mathrm{FO}$ or $\mathrm{OO}$ during the first 4 months after delivery ${ }^{(19)}$. The offspring were examined at the age of 2.5 years and, in accordance with the present study, FO supplementation was not associated with significant BP effects. When the children were re-examined at the age of 7 years, there was a significant adverse effect of $\mathrm{FO}$ as compared to $\mathrm{OO}$ supplementation on mean BP and diastolic BP in boys only ${ }^{(20)}$. BP was, however, not significantly associated with the content of long-chain $n$-3 PUFA in maternal erythrocytes 4 months after delivery, and the authors argued that the FO effect found simply could be due to chance.

A randomised trial, where infants were randomised to formula with long-chain $n$ - 3 and $n$ - 6 PUFA or similar formula without supplementation $^{(18)}$, found that diastolic BP and mean BP at the age of 6 years were significantly lower in the group receiving the supplemented formulae. Due to the very low concentration of long-chain $n$-3 PUFA in the control supplement, it is possible that the infants receiving the control supplements were deficient in long-chain $n$-3 PUFA. This might explain the different result in our study where most of the pregnant women had a medium-to-high intake of fish and very few would be expected to be deficient in long-chain $n$-3 PUFA. However, stratification on baseline fish intake did not change estimates significantly in the present study. 
Finally, a randomised study in human subjects with an intervention aimed at increasing dietary intake of long-chain $n$-3 PUFA and decreasing intake of $n-6$ PUFA from the time of weaning until the age of 5 years found no significant effect of intervention type on BP at 8 years of age ${ }^{(21)}$.

One study has examined the effect of long-chain $n$-3 PUFA supplementation in preterm infants ${ }^{(26)}$. Preterm infants were randomised to unsupplemented or long-chain $n-3$ and $n-6$ PUFA-supplemented formula until 9 months after delivery, and an adverse effect of supplementation on BP was found at 10 years of age, but only in girls. The effect disappeared after adjustment for current weight, indicating that it may be mediated by supplementation effects on body size.

In observational studies and randomised trials, breast-feeding or donated banked breast milk has been shown to be associated with a lower BP in the child or adolescents ${ }^{(27,28)}$. Breast milk has a relatively high concentration of long-chain $n-3$ PUFA, and it has been suggested that this association is caused by long-chain $n-3$ PUFA. However, breast-feeding is also associated with a lower overall energy intake of the infants, and this could also be a possible explanation for the association found $^{(29)}$.

Early long-chain $n$-3 PUFA might, however, also play a role in the programming of later BP. In a study by Dirix et $a l .{ }^{(30)}$ a positive association between the relative contents of DHA in maternal phospholipids early in pregnancy (but not later) and birth weight was found. Birth weight has been shown to be associated with later BP and hence it is possible that supplementing with FO during early pregnancy could affect later BP.

The $24 \mathrm{~h} \mathrm{HRV}$ indices measured in the present study were comparable to those previously measured in young healthy subjects, for both males and females ${ }^{(31)}$. To our knowledge, no other study has looked into the long-term effect of FO supplementation during pregnancy on later HR and HRV. The effect of long-chain $n$-3 PUFA supplementation during infancy on later HR and HRV has, however, been investigated in two studies. No effect of supplementing with long-chain PUFA during infancy was found on HR in the 10-year follow-up of a study with preterm infants ${ }^{(26)}$. Also, in the study by Larnkjær et $a l^{(19)}$, no overall effect of FO supplementation to lactating mothers was found on HR and HRV in the 2.5-year-old offspring. There were, however, indications of an effect of FO supplementation on HR as well as the HRV component SDANN in girls, though we found no such association. We followed-up on the participants for a longer time, and found that they had been subjected to a larger influence from lifestyle factors, which might have attenuated any short-term effects. Also, the $24 \mathrm{~h} \mathrm{HRV}$ measurements were only done in offspring of mothers with a low baseline fish intake. Unfortunately, only thirty-seven agreed to participate (of a total of eighty-one subjects), and due to the large variation in HRV measurements it cannot be ruled out that this may be the reason why no significant effect of FO supplementation was found in the present study (type 2 error). Hence, this study was only powered to detect a difference in RR of $76 \mathrm{~ms}$ which is well above the differences previously detected for the short-term effects of FO. The no-effect finding, however, is supported by the lack of any overall effect of $\mathrm{FO}$ supplementation on $\mathrm{HR}_{\mathrm{BP}}$,
$\mathrm{SDNN}_{2 \mathrm{~min}}$ and $\mathrm{HR}_{\mathrm{E} / \mathrm{I}}$, which were measured in all participants. The observed effect of $\mathrm{FO}$ on $\mathrm{HR}_{\mathrm{E} / \mathrm{I}}$ in offspring of women with a high baseline fish intake is surprising and we believe that it most probably relates to a chance finding. A large amount of analyses have been performed in the study, increasing the risk of a type 1 error.

In conclusion, compared to OO, FO supplementation during the third trimester of pregnancy was not significantly associated with offspring BP, HR and HRV in the 19-year-old offspring. This was also true when the analyses were stratified by sex and baseline fish intake.

\section{Acknowledgements}

The project described was supported by award number R21AT004603 from the National Center for Complementary \& Alternative Medicine. The content is solely the responsibility of the authors and does not necessarily represent the official views of the National Center for Complementary \& Alternative Medicine or the National Institutes of Health. In addition, the follow-up study was supported by The Danish Strategic Research Council (grant nos.: 09-067124, 2101-07-0025 and 2101-06-0005), the EU FP6 consortium, Early Nutrition Programming Project (EARNEST, project no. FOOD-CT-2005007036, The Danish Heart Foundation, The Novo Nordisk Foundation, The Danish Diabetes Foundation and The Aase and Ejnar Danielsens Foundation. The study sponsors were not involved in the study design; in the collection, analysis or interpretation of data; in the writing of the report, or in the decision to submit the manuscript for publication. The authors' contributions to the present study were as follows: S. F. O. was responsible for the original pregnancy trial and initiated the follow-up of the offspring. D. R., J. H. C., B. H. B., S. F. O., E. B. S. and T. B. H. designed the research; D. R. and B. H. B. conducted the research; D. R. analysed the data and wrote the first draft; D. R., J. H. C., S. F. O., E. B. S., B. H. B. and T. B. H. wrote the paper; D. R. had primary responsibility for the final content. All authors read and approved the final manuscript. None of the authors had a conflict of interest.

\section{References}

1. Schmidt EB, Arnesen H, Christensen JH, et al. (2005) Marine $n-3$ polyunsaturated fatty acids and coronary heart disease: part II. Clinical trials and recommendations. Thromb Res 115, 257-262.

2. Calder PC (2004) n-3 Fatty acids and cardiovascular disease: evidence explained and mechanisms explored. Clin Sci (Lond) 107, 1-11.

3. Dahl L, Bjorkkjaer T, Graff IE, et al. (2006) Fish-more than just omega 3. Tidsskr Nor Laegeforen 126, 309-311.

4. Mori TA (2010) Omega-3 fatty acids and blood pressure. Cell Mol Biol (Noisy-le-grand) 56, 83-92.

5. Geleijnse JM, Giltay EJ, Grobbee DE, et al. (2002) Blood pressure response to fish oil supplementation: metaregression analysis of randomized trials. $J$ Hypertens 20, 1493-1499.

6. Mozaffarian D, Geelen A, Brouwer IA, et al. (2005) Effect of fish oil on heart rate in humans: a meta-analysis of randomized controlled trials. Circulation 112, 1945-1952. 
7. Christensen JH \& Schmidt EB (2007) Autonomic nervous system, heart rate variability and $n-3$ fatty acids. J Cardiovasc Med (Hagerstown) 8, Suppl. 1, S19-S22.

8. Christensen JH, Svensson M, Strandhave C, et al. (2010) n-3 Fatty acids and cardiac autonomic function in humans. Cell Mol Biol (Noisy-le-grand) 56, 131-139.

9. Holguin F, Tellez-Rojo MM, Lazo M, et al. (2005) Cardiac autonomic changes associated with fish oil vs soy oil supplementation in the elderly. Chest $\mathbf{1 2 7}$, $1102-1107$

10. Tsuji H, Larson MG, Venditti FJ Jr, et al. (1996) Impact of reduced heart rate variability on risk for cardiac events. The Framingham Heart Study. Circulation 94, 2850-2855.

11. Barker DJ (2008) Human growth and cardiovascular disease. Nestle Nutr Workshop Ser Pediatr Program 61, 21-38.

12. Uauy R, Peirano P, Hoffman D, et al. (1996) Role of essential fatty acids in the function of the developing nervous system. Lipids 31, S167-S176.

13. Armitage JA, Pearce AD, Sinclair AJ, et al. (2003) Increased blood pressure later in life may be associated with perinatal n-3 fatty acid deficiency. Lipids 38, 459-464.

14. Weisinger HS, Armitage JA, Sinclair AJ, et al. (2001) Perinatal omega-3 fatty acid deficiency affects blood pressure later in life. Nat Med 7, 258-259.

15. Massin M \& von Bernuth G (1997) Normal ranges of heart rate variability during infancy and childhood. Pediatr Cardiol 18, 297-302.

16. Lauritzen L, Christensen JH, Damsgaard CT, et al. (2008) The effect of fish oil supplementation on heart rate in healthy Danish infants. Pediatr Res 64, 610-614.

17. Damsgaard CT, Schack-Nielsen L, Michaelsen KF, et al. (2005) Fish oil affects blood pressure and the plasma lipid profile in healthy Danish infants. J Nutr 136, 94-99.

18. Forsyth JS, Willatts P, Agostoni C, et al. (2003) Long chain polyunsaturated fatty acid supplementation in infant formula and blood pressure in later childhood: follow up of a randomised controlled trial. BMJ 326, 953.

19. Larnkjaer A, Christensen JH, Michaelsen KF, et al. (2006) Maternal fish oil supplementation during lactation does not affect blood pressure, pulse wave velocity, or heart rate variability in 2.5-y-old children. J Nutr 136, 1539-1544.

20. Asserhoj M, Nehammer S, Matthiessen J, et al. (2009) Maternal fish oil supplementation during lactation may adversely affect long-term blood pressure, energy intake, and physical activity of 7-year-old boys. J Nutr 139, 298-304.

21. Ayer JG, Harmer JA, Xuan W, et al. (2009) Dietary supplementation with $n-3$ polyunsaturated fatty acids in early childhood: effects on blood pressure and arterial structure and function at age 8 y. Am J Clin Nutr 90, $438-446$

22. Olsen SF, Sorensen JD, Secher NJ, et al. (1992) Randomised controlled trial of effect of fish-oil supplementation on pregnancy duration. Lancet 339, 1003-1007.

23. Ejskjaer N, Fleischer J, Fleischer J, et al. (2008) A pocket-size device to detect autonomic neuropathy. J Diabetes Sci Technol 2, 692-696.

24. Fleischer J, Nielsen R, Laugesen E, et al. (2011) Self-monitoring of cardiac autonomic function at home is feasible. J Diabetes Sci Technol 5, 107-112.

25. Salvig JD, Olsen SF \& Secher NJ (1996) Effects of fish oil supplementation in late pregnancy on blood pressure: a randomised controlled trial. Br J Obstet Gynaecol 103, $529-533$

26. Kennedy K, Ross S, Isaacs EB, et al. (2010) The 10-year follow-up of a randomised trial of long-chain polyunsaturated fatty acid supplementation in preterm infants: effects on growth and blood pressure. Arch Dis Child 95, $588-595$.

27. Wilson AC, Forsyth JS, Greene SA, et al. (1998) Relation of infant diet to childhood health: seven year follow up of cohort of children in Dundee infant feeding study. BMJ 316, 21-25.

28. Singhal A, Cole TJ \& Lucas A (2001) Early nutrition in preterm infants and later blood pressure: two cohorts after randomised trials. Lancet 357, 413-419.

29. Singhal A \& Lucas A (2004) Early origins of cardiovascular disease: is there a unifying hypothesis? Lancet 363 $1642-1645$.

30. Dirix CE, Kester AD \& Hornstra G (2009) Associations between neonatal birth dimensions and maternal essential and trans fatty acid contents during pregnancy and at delivery. Br J Nutr 101, 399-407.

31. Bonnemeier H, Richardt G, Potratz J, et al. (2003) Circadian profile of cardiac autonomic nervous modulation in healthy subjects: differing effects of aging and gender on heart rate variability. J Cardiovasc Electrophysiol 14, 791-799.

32. Rytter D, Bech BH, Christensen JH, et al. (2011) Intake of fish oil during pregnancy and adiposity in 19-y-old offspring: follow-up on a randomized controlled trial. Am J Clin Nutr 94, 701-708.

33. Rytter D, Schmidt EB, Bech BH, et al. (2011) Fish oil supplementation during late pregnancy does not influence plasma lipids or lipoprotein levels in young adult offspring. Lipids 46, 1091-1099. 